This is the peer reviewed version of the following article: Cairney, P., Oliver, K. and Wellstead, A. (2016), To Bridge the Divide between Evidence and Policy: Reduce Ambiguity as Much as Uncertainty. Public Administration Review, 76: 399-402, which has been published in final form at http://onlinelibrary.wiley.com/doi/10.1111/puar.12555/abstract. This article may be used for non-commercial purposes in accordance With Wiley Terms and Conditions for self-archiving. 
Paul Cairney, Kathryn Oliver, Adam Wellstead p.a.cairney@stir.ac.uk 26 Jan 2016

Forthcoming in Public Administration Review's Evidence in Public Administration series

\section{To bridge the divide between evidence and policy: reduce ambiguity as much as uncertainty}

\section{Practitioner Points}

- The natural science literature, on how to maximize the use of evidence in policy, should learn from studies of public policy and administration

- Lesson one: identify 'where the action is' in multi-level policymaking environments

- Lesson two: supplement the use of evidence to reduce policymaker uncertainty with persuasion to reduce ambiguity

\section{Introduction}

There is now a large literature on the gaps between the production of scientific evidence and a policymaking response. However, in disciplines such as health and environmental sciences, most studies do not use insights from policy theory, public administration, or organizational studies to explain the gap. Focusing on policy theory, we explain why this matters by identifying the difference between empirical uncertainty and policy ambiguity. Both concepts relate to 'bounded rationality': policymakers do not have the ability to consider all evidence relevant to policy problems. Instead, they employ two shortcuts: 'rational', by pursuing clear goals and prioritizing certain kinds and sources of information, and 'irrational', by drawing on emotions, gut feelings, deeply held beliefs, and habits to make decisions quickly. This takes place in an unpredictable policymaking environment in which attention can lurch from issue to issue, policy is made routinely in networks, and the 'rules of the game' take time to learn.

The key problem with many studies is that they focus only on the first short cut. They only identify the problem of uncertainty and incomplete information, and seek to solve it by creating hierarchies of evidence, improving the supply of information to policymakers, and encouraging academic-practitioner workshops. They ignore the wider process of debate, coalition formation, and persuasion, to reduce ambiguity by establishing a dominant way to 'frame' policy problems. The latter can determine the demand for scientific evidence. Therefore, an additional solution for advocates of scientific evidence is to engage in a process of persuasion by, for example, forming coalitions with allies with the same aims or beliefs, and working with them to combine evidence with simple stories to exploit the emotional and ideological biases of policymakers.

We demonstrate this argument in three steps. First, we outline two systematic reviews of the literature on 'barriers' to evidence and policy. Most studies present solutions to reduce uncertainty. Second, we derive key insights from a wide range of policy concepts and theories (hereafter 'policy theory') to show the effect of unpredictable policy environments on the use of evidence and, therefore, the importance of ambiguity and persuasion. Third, our 
conclusion explores the implications for the role of science and experts in policymaking. We identify the practical, normative, and ethical consequences for actors trying to maximize the uptake of scientific evidence within government.

\section{Limited insights from existing studies: improve the evidence, reduce uncertainty}

We use the examples of health and environmental sciences, in which scientific advocates express frustration at their limited ability to promote evidence-based solutions to urgent policy problems. The most frequently-reported source of barriers relate to the lack of time, support, resources, and incentives for scientists to disseminate high quality information effectively (Oliver et al, 2014a; Cairney, 2015). Studies also identify the low policy relevance in academic research and minimal academic knowledge about how to be strategic, such as to identify relevant policymakers and opportunities for timely engagement (Stringer and Dougill, 2013). They highlight differences in academic and political 'cultures': language and jargon, longer scientific timescales, low incentives to engage, differing perceptions of scientific knowledge, and the relative need for scientists to challenge evidence (to ensure it is robust) but for policymakers to generate an image of policy certainty and reconcile evidence with well-established beliefs. There is also a perception that policymakers rely on personal experience, ad hoc links with experts, people they know and trust, and simple decisionmaking techniques and stories, rather than the state-of-the-art in scientific research and sophisticated modelling systems (Lomas and Brown, 2009: 906).

The proposed solutions to this cultural gap are very similar in health and environmental studies: improve the evidence base on policy solutions; 'package' the evidence well, to make it easy to understand, framed in a way that is attractive to policymakers, and/ or accompanied by realistic expectations for policy change; foster networks with policymakers and encourage academic-practitioner workshops; use intermediaries such as 'knowledge brokers'; recognise the importance of timing; and, encourage policymaker skills or better government understanding of problems (Cvitanovic et al, 2015).

Very few of these studies draw on policy theory or other sources of knowledge of the policy process such as public administration or organisational studies. Most are based on personal experiences, producing incomplete findings because the evidence is limited to interviewees with minimal knowledge of policymaking. Or, they draw on outmoded understandings of policymaking, including: policy cycles, containing a core group of policymakers at the 'centre' and clearly defined and well-ordered stages; and, the sense that advances in scientific evidence-gathering can minimize the problem of 'bounded rationality' (Cairney, 2016). Such discussions suggest that scientists can improve the use of evidence in policy, in a relatively straightforward way, by identifying a core group of policymakers and using the best scientific information to reduce policymaker uncertainty.

\section{Lessons from policy theory: 1. Identify multi-level policymaking environments}

Policy theory helps us fill two key gaps in such analysis. First, policymaking takes place in less ordered and predictable policy environment, exhibiting: 
- a wide range of actors (individuals and organisations) influencing policy at many levels of government

- a proliferation of rules and norms followed by different levels or types of government

- close relationships ('networks') between policymakers and powerful actors

- a tendency for certain beliefs or 'paradigms' to dominate discussion

- shifting policy conditions and events that can prompt policymaker attention to lurch at short notice.

A focus on this bigger picture shifts our attention from the use of scientific evidence by an elite group of elected policymakers at the 'top' to its use by a wide range of influential actors in a multi-level policy process. It shows scientists that they are competing with many actors to present evidence in a particular way to secure a policymaker audience. Support for particular solutions varies according to which organisation takes the lead and how it understands the problem. Some networks are close-knit and difficult to access because bureaucracies have operating procedures that favour particular sources of evidence and some participants over others, and there is a language - indicating what ways of thinking are in good 'currency' (such as 'value for money') - that takes time to learn. Well-established beliefs provide the context for policymaking: new evidence on the effectiveness of a policy solution has to be accompanied by a shift of attention and successful persuasion. In some cases, social or economic 'crises' can prompt lurches of attention from one issue to another, and some forms of evidence can be used to encourage that shift.

In this context, too many studies analyse, for example, a singular point of central government decision rather than the longer term process (Oliver et al, 2014a: 10). Overcoming barriers to influence in that small part of the process will not provide an overall solution.

\section{Lessons from policy theory: 2 . Use evidence and persuasion to reduce ambiguity}

Significant advances in scientific practice, knowledge and systematic review address only one aspect of bounded rationality: the reduction of uncertainty (Botterill and Hindmoor, 2012: 371). They do not address others, such as the inability to completely separate empirical facts from human values and ways of thinking. All individuals combine goal-driven and evidence-informed strategies with moral or emotional judgements based on their wellestablished beliefs, and informational shortcuts based on their familiarity with information and sources of information (Kahneman, 2012: 20; Haidt, 2001: 818; Alter and Oppenheimer, 2009; Schneider et al, 2014).

Consequently, the focus of policy theory is on the links between evidence, persuasion, and framing (in the wider context of a tendency for certain beliefs to dominate discussion). Framing refers to the ways in which actors understand, portray, and categorise issues (Cairney, 2012: 185). Problems are multi-faceted, but bounded rationality limits the attention of policymakers, and actors compete to highlight one image at the expense of others. The outcome of this process determines who is involved (for example, portraying an issue as technical limits involvement to experts), and responsible for policy, how much attention they pay, and what kind of solution they favour. For example, tobacco control is more likely when 
policymakers view it primarily as a public health epidemic rather than an economic good, while 'fracking' policy depends on its primary image as a new energy boom or environmental disaster.

Scientific evidence plays a part in this process, but we should not exaggerate the ability of scientists to win the day with reference to evidence. Rather, policy theory signals the strategies that practitioners may have to adopt to increase demand for their evidence:

- combine facts with emotional appeals, to prompt lurches of policymaker attention from one policy image to another (True et al, 2007: 161)

- tell simple stories which are easy to understand, help manipulate people's biases, apportion praise and blame, and highlight the moral and political value of solutions (Jones et al, 2014)

- interpret new evidence through the lens of the pre-existing beliefs of actors within coalitions, some of which dominate policy networks (Weible et al, 2012)

- produce a policy solution that is feasible and exploit a time when policymakers have the opportunity to adopt it (Kingdon, 1984).

Further, the impact of a framing strategy is not necessarily immediate even if it is successful. Scientific evidence may prompt a lurch of attention to a policy problem, prompting a shift of views in one venue or the new involvement of actors from other venues. However, it can take years to produce support for an 'evidence-based' policy solution, built on its technical and political feasibility (will it work as intended, and do policymakers have the motive and opportunity to select it?).

\section{Concluding discussion: key strategies for advocates of evidence-based policymaking}

Policymaking takes place in an often unpredictable environment in which many actors make and influence policy, using 'rational' and 'irrational' short cuts to make decisions quickly. From policy theory, we can identify pragmatic ways to adapt to, and engage in, this process: identify where the action is (in subsystems and venues in several levels of government); learn and follow the 'rules of the game' of subsystems to improve strategies and help build up trust; form coalitions with actors with similar aims and beliefs; and, frame the evidence to appeal to the biases, beliefs, and priorities of policymakers (Stoker, 2010: 55-7; Cairney, 2015; Weible et al, 2012). Meaningful influence requires a long term strategy to form alliances and develop knowledge of policymakers and policymaking, not a one-off dissemination of state-of-the-art knowledge.

Consequently, scientists have a difficult choice to make, between the need to specialize and maintain an image of academic objectivity, or go beyond their comfort zone, and expertise, to engage in an advocacy enterprise to increase impact. Without such advocacy, policymakers will rely on highly biased and persuasive stories from vested interests, rather than struggle through inaccessible and equivocal scientific papers.

Of course, there is a huge difference between identifying this advice and expecting practitioners such as scientists to be in a position to follow it. Instead, we offer four pragmatic 
suggestions. First, the existing literature is correct to promote networks between communities of scientists and policymakers. Networks allow both sides to learn to appreciate the constraints under which they, and the other camp, operate. Academics must be open to conversations about the political value and risks of the information they generate. Policymakers must acknowledge that being explicit about the scientific uncertainty inherent in any study is absolutely essential to the intellectual credibility of individual academics and academic work. While policymakers can be frustrated by the reluctance of academics to make unequivocal policy recommendations, we need respectful conversation which allows political judgment to be truly informed by evidence, without academics feeling undue pressure to kowtow or be silenced. Further, academics must come to feel comfortable that their advice and expertise is valued even if the knowledge being shared is months or years old; a life-time of expertise can be as valuable to a policymaker as a brand-new study. For academics, this should soften the apparent choice between advocacy and impact, on the one hand, and isolationist but credible academic activity. What is required is a thoughtful dialogue about the responsibilities each set of actors have to themselves, their practices, and their constituencies, whether voters or research participants. Both sides have much to learn about and from each other, and working more closely together can help both sides to deliver more relevant, useful, and effective policy.

Second, there may be ways to improve these links by overcoming barriers to engagement. There is much to be gained from closer collaboration based on new incentives for both groups. Creating opportunities which are rewarded (e.g. by promotions) for 'co-production' of policy or policy-relevant research, would be an obvious way to enable coalition-building. Academics would be enabled to do more policy-relevant research if they were more aware of the upcoming policy agendas; they would be able to present their research to the right audiences if this (and training) were enabled by funders and valued by universities; and if more time were made available to both camps to allow conversations, even without specific policy targets in mind. Reducing the current waste of time and resources in the scientific funding models we currently use would be one way of resourcing these conversations.

Third, in some fields there is a tendency to use generalist intermediaries or 'knowledge brokers', and this may be an economic solution even if the evidence of their effectiveness is mixed. What seems to matter is the ability to know who to ask which question, and having a sufficiently good and ongoing relationship to be able to call on academic or policy experts when needed (Oliver et al, 2016).

However, finally, it is important to draw insights from policy studies to help us recognize the profound limits to each of these strategies, and to relate them to nascent policy agendas on measuring the practical value of academic research. There is an increasing focus, particularly in countries such as the UK, on demonstrating academic 'impact' on policy and policymaking. This involves a linear and short-term process of engagement and impact which can be described simply enough in University reports to justify economic rewards for academic activity. Yet, our discussion shows how short-sighted and box-ticking such exercises may become. Meaningful policy impact built on academic-policymaker relationships take time and effort to create and maintain. It cannot simply be bought, 
outsourced, or produced during ad hoc workshops. Further, in a complex policymaking system, it makes little sense to pinpoint discrete examples of academic influence. There are ways to produce meaningful academic-policymaker engagement, but we should not exaggerate its impact or our ability to measure it in a simple way.

\section{References}

Alter, Adam and Oppenheimer, Daniel "Uniting the tribes of fluency to form a metacognitive nation”, Personality and Social Psychology Review 13, no. 3 (2009): 219-235

Botterill, Linda and Hindmoor, Andrew "Turtles all the way down: bounded rationality in an evidence-based age", Policy Studies 33, no. 5 (2012): 367-379

Cairney, Paul Understanding Public Policy (Basingstoke: Palgrave, 2012)

Cairney, Paul The Politics of Evidence-based Policymaking (London: Palgrave Pivot, 2016)

Cvitanovic, Christopher, Hobday, van Kerkhoff, Lorrae, Wilson, Shaun, Dobbs, Kirsten and Nadine Marshall. "Improving knowledge exchange among scientists and decision-makers to facilitate the adaptive governance of marine resources: A review of knowledge and research needs." Ocean \& Coastal Management 112 (2015): 25-35.

Haidt, Jonathan. "The emotional dog and its rational tail: a social intuitionist approach to moral judgment." Psychological review 108, no. 4 (2001): 814.

Jones, Michael D., Elizabeth A. Shanahan, and Mark K. McBeth, eds. The Science of Stories: Applications of the Narrative Policy Framework in Public Policy Analysis. Palgrave Macmillan, 2014.

Kahneman, Daniel (2012) Thinking Fast and Slow (London: Penguin, 2012)

Kingdon, John, Agendas, Alternatives and Public Policies (New York, NY: Harper Collins, 1984)

Lomas, Jonathan, and Adalsteinn D. Brown. "Research and advice giving: A functional view of evidence-informed policy advice in a Canadian Ministry of Health." Milbank Quarterly 87, no. 4 (2009): 903-926.

Nilsson, Måns, Andrew Jordan, John Turnpenny, Julia Hertin, Björn Nykvist, and Duncan Russel. "The use and non-use of policy appraisal tools in public policy making: an analysis of three European countries and the European Union." Policy Sciences 41, no. 4 (2008): 335355.

Oliver, Kathryn, Simon Innvar, Theo Lorenc, Jenny Woodman, and James Thomas. "A systematic review of barriers to and facilitators of the use of evidence by policymakers." BMC health services research 14, no. 1 (2014): 2 http://www.biomedcentral.com/1472$\underline{6963 / 14 / 2}$ 
Oliver, Kathryn, Theo Lorenc, and Simon Innvær. "New directions in evidence-based policy research: a critical analysis of the literature." Health Res Policy Syst 12 (2014): 34.http://www.biomedcentral.com/content/pdf/1478-4505-12-34.pdf

Oliver, K. et al (2016) TBC

Schneider, Anne, Ingram, Helen, and Peter deLeon, 'Democratic Policy Design: Social Construction of Target Populations' in Sabatier, Paul and Weible, Chris (eds.) Theories of the Policy Process $3^{\text {rd }}$ edition (Boulder, CO: Westview Press, 2014)

Stoker, Gerry. "Translating experiments into policy." The ANNALS of the American Academy of Political and Social Science 628, no. 1 (2010): 47-58.

Stringer, Lindsay C., and Andrew J. Dougill. "Channelling science into policy: Enabling best practices from research on land degradation and sustainable land management in dryland Africa." Journal of environmental management 114 (2013): 328-335.

True, James L., Bryan D. Jones, and Frank R. Baumgartner. "Punctuated Equilibrium Theory: Explaining Stability and Change in Public Policymaking in P. Sabatier (ed.) Theories of the Policy Process, 2nd ed (Cambridge, MA: Westview Press, 2007)

Weible, Christopher M., Tanya Heikkila, and Paul A. Sabatier. "Understanding and influencing the policy process." Policy Sciences 45, no. 1 (2012): 1-21.

Wellstead, Adam, and Richard Stedman. "Addressing the Challenges of Adaptation to Climate Change Policy: Integrating Public Administration and Public Policy Studies." International Journal of Public Administration 37, no. 14 (2014): 999-1010. 